\title{
TINJAUAN DAYA DUKUNG PONDASI SUMURAN PADA GEDUNG-X DI KOTA BUKITTINGGI
}

\author{
Asri Yuda Trinanda ${ }^{1^{*}}$
}

1) Universitas Putra Indonesia "YPTK" Padang Sumatera Barat Indonesia (email : asriyuda93@gmail.com)

\section{Info Artikel}

Riwayat Artikel:

Dikirim : 26-05-2021

Direvisi : 24-06-2021

Diterbitkan : 28-06-2021

\section{Keywords :}

Pondasi,

Sumuran,

Daya Dukung,

Metode Terzaghi,

Metode Meyerhof.

\begin{abstract}
$\underline{\text { ABSTRAK }}$
Suatu konstruksi terdiri dari struktur atas dan struktur bawah. Masing-masing elemen struktur berfungsi dalam menahan seluruh beban yang bekerja pada bangunan tersebut. Struktur bawah yang terdiri dari pondasi, menjadi tumpuan seluruh beban-beban yang bekerja di atas bangunan tersebut. Jenis pondasi yang digunakan tergantung pada pemilihan tipe struktur, beban yang bekerja dan jenis tanahnya. Salah satu jenis pondasi pada konstruksi adalah pondasi sumuran. Penelitian ini akan menganalisis tentang kapasitas dari pondasi sumuran pada proyek pembangunan gedung $\mathrm{X}$ di Kota Bukittinggi. Dalam perhitungan kapasitas daya dukung pondasi menggunakan dua metode, yaitu metode Terzaghi dan metode Meyerhof. Perhitungan dilakukan terhadap satu tipe dimensi pondasi diameter 1,2 $\mathrm{m}$ dengan kedalaman tiga meter. Dari hasil analisis yang dilakukan terhadap daya dukung pondasi, diperoleh daya dukung pondasi dengan metode Terzaghi sebesar $2524,3 \mathrm{kN}$. Sedangkan daya dukung yang diperoleh dengan metode Meyerhof adalah 1759,57 . Adanya perbedaan nilai daya dukung ijin pada metode Terzaghi dan metode Meyerhof karena penambahan koefisien-koefisien pada metode tersebut. Pada metode Terzaghi memperhitungkan faktor bentuk pondasi (sc dan $\mathrm{s} \gamma$ ). Sedangkan metode Meyerhof dipengaruhi oleh faktor kedalaman pondasi (dc, $\mathrm{dq}, \mathrm{d} \gamma$ ), faktor bentuk pondasi (sc, sq, s $\gamma$ ), dan faktor kemiringan beban (ic, iq, i $\gamma$ ).
\end{abstract}

\section{PENDAHULUAN}

Secara umum terdapat dua jenis pondasi, yaitu pondasi dangkal dan pondasi dalam. Pemilihan pondasi suatu bangunan tergantung pada jenis struktur, beban-beban dan jenis tanahnya. Untuk konstruksi beban ringan biasanya dipakai pondasi dangkal, dan untuk konstruksi dengan beban yang besar, umumnya digunakan pondasi dalam. Salah satu jenis pondasi adalah pondasi sumuran. Pondasi sumuran merupakan jenis pondasi peralihan antara pondasi dangkal dan pondasi tiang, digunakan apabila tanah dasar terletak pada kedalaman yang cukup dalam.

Daya dukung pondasi sumuran diperoleh dari daya dukung ujung (end bearing capacity) yang diperoleh dari tekanan ujung tiang dan daya dukung geser atau selimut (friction bearing capacity) yang diperoleh dari daya dukung geser datau gaya adhesi antara pondasi sumuran dan tanah disekelilingnya.

Menurut Asroni (2010), struktur bangunan dibagi menjadi 2 bagian utama, yaitu struktur bangunan di dalam tanah dan struktur bangunan diatas tanah. Struktur bangunan di dalam tanah sering disebut struktur bawah, sedangkan struktur di atas tanah disebut struktur atas. Struktur bawah dari suatu 
bangunan umumnya disebut dengan pondasi, yang berfungsi untuk memikul seluruh bebanbeban diatasnya untuk diteruskan oleh pondasi ke tanah dasar.

Pondasi harus direncanakan dengan teliti terhadap seluruh beban-beban yang akan ditahan. Perencanaan pondasi harus diperhitungkan terhadap beban gravitasi dan beban lateral. Beban gravitasi merupakan beban vertikal yang berasal dari struktur bangunan, seperti beban mati (termasuk berat sendiri bangunan), dan beban hidup. Sedangkan, beban lateral merupakan beban horizontal yang berasal dari luar struktur bangunan, seperti beban angin dan beban gempa.

\section{METODOLOGI PENELITIAN}

\subsection{Lokasi Penelitian}

Penelitian ini dilakukan terhadap salah satu gedung $\mathrm{X}$ di Kota Bukittinggi. Gedung X merupakan gedung bertingkat yang digunakan untuk pendidikan.

\subsection{Pengumpulan Data}

Penelitian dilakukan terhadap kapasitas satu tipe pondasi sumuran yang dipakai pada bangunan tersebut. Sebelum dilakukan analisis terhadap pondasi, terlebih dahulu dilakukan pengumpulan data-data yang pendukung dari penelitian ini. Data sekunder adalah data yang diperoleh dari instansi terkait yang berkaitan dengan penelitian ini. Data sekunder yang digunakan dalam penelitian ini meliputi :

- Data penyelidikan tanah; dan

- Data pondasi (gambar detail pondasi).

\subsection{Pengolahan Data}

\section{Daya Dukung Pondasi Metode Terzaghi}

Persamaan daya dukung pondasi sumuran hampir sama dengan persamaan yang digunakan untuk menghitung daya dukung pondasi tiang pancang. Daya dukung pondasi sumuran juga ditentukan oleh daya dukung tanah dasar gesekan (f) dan atau lekatan (c). Untuk menghitung daya dukung ultimate tanah dasar dapat digunakan persamaan Terzaghi berikut.

$$
\mathrm{q}_{\mathrm{ult}}=\mathrm{sc} \cdot \mathrm{c} \cdot \mathrm{Nc}+\mathrm{Df} \cdot \gamma_{1} \cdot \mathrm{Nq}+\mathrm{s} \gamma \cdot \mathrm{B} \cdot \gamma_{2} \cdot \mathrm{N} \gamma
$$

Untuk pondasi bentuk bujur sangkar/segi empat

$\mathrm{q}_{\mathrm{ult}}=1,3 \cdot \mathrm{c} \cdot \mathrm{Nc}+$ Df. $\gamma_{1} \cdot \mathrm{Nq}+0,8 \cdot \mathrm{B} \cdot \gamma_{2} \cdot \mathrm{N}_{\gamma}$

Untuk pondasi bentuk lingkaran

$\mathrm{q}_{\text {ult }}=1,3 \cdot \mathrm{c} \cdot \mathrm{Nc}+$ Df. $\gamma_{1} \cdot \mathrm{Nq}+0,6 \cdot \mathrm{B} \cdot \gamma_{2} \cdot \mathrm{N}_{\gamma}$

dengan :

$\mathrm{q}_{\mathrm{ult}} \quad=$ daya dukung ultimate pondasi

c = kohesi tanah

$\gamma_{1}=$ berat vol. tanah disamping pondasi

$\gamma_{2}=$ berat vol. tanah dibawah pondasi

Df $\quad=$ kedalaman sampai dasar pondasi

$\mathrm{B}=$ Lebar pondasi

$\mathrm{Nc}, \mathrm{Nq}, \mathrm{N} \gamma=$ faktor daya dukung terzaghi

Tabel 1. Faktor Daya Dukung Terzaghi

\begin{tabular}{ccccccc}
\hline$\Phi$ & $\mathrm{Nc}$ & $\mathrm{Nq}$ & $\mathrm{N}_{\gamma}$ & $\mathrm{Nc}^{\prime}$ & $\mathrm{Nq}^{\prime}$ & $\mathrm{N}_{\gamma}{ }^{\prime}$ \\
\hline 0 & 5,7 & 1,0 & 0,0 & 5,7 & 1,0 & 0,0 \\
\hline 5 & 7,3 & 1,6 & 0,5 & 6,7 & 1,4 & 0,2 \\
\hline 10 & 9,6 & 2,7 & 1,2 & 8,0 & 1,9 & 0,5 \\
\hline 15 & 12,9 & 4,4 & 2,5 & 9,7 & 2,7 & 0,9 \\
\hline 20 & 17,7 & 7,4 & 5,0 & 11,8 & 3,9 & 1,7 \\
\hline 25 & 25,1 & 12,7 & 9,7 & 14,8 & 5,6 & 3,2 \\
\hline 30 & 37,2 & 22,5 & 19,7 & 19,0 & 8,3 & 5,7 \\
\hline 34 & 52,6 & 36,5 & 35,0 & 23,7 & 11,7 & 9,0 \\
\hline 35 & 57,8 & 41,4 & 42,4 & 25,2 & 12,6 & 10,1 \\
\hline 40 & 95,7 & 81,3 & 100,4 & 34,9 & 20,5 & 18,8 \\
\hline 45 & 172,3 & 173,3 & 297,5 & 51,2 & 35,1 & 37,7 \\
\hline 50 & 347,6 & 415,1 & 1153,2 & 81,3 & 65,6 & 87,1 \\
\hline \multicolumn{5}{l}{ Sumber : Hakam, $(2008)$} & &
\end{tabular}

Tabel 2. Faktor Bentuk untuk Rumus Daya Dukung Terzaghi

\begin{tabular}{cccc}
\hline $\begin{array}{c}\text { Faktor } \\
\text { Bentuk }\end{array}$ & \multicolumn{3}{c}{ Bentuk Pondasi } \\
\cline { 2 - 4 } & $\begin{array}{c}\text { Menerus } \\
(\mathrm{L}>>\mathrm{B})\end{array}$ & $\begin{array}{c}\text { Bujur } \\
\text { Sangkar } \\
(\mathrm{L}=\mathrm{B})\end{array}$ & $\begin{array}{c}\text { Lingkaran } \\
(\text { diameter } \\
=\mathrm{B})\end{array}$ \\
\hline $\mathbf{S c}$ & 1.0 & 1.3 & 1.3 \\
\hline $\mathbf{S} \gamma$ & 1.0 & 0.8 & 0.6 \\
\hline Sumber : Hakam, (2008) & &
\end{tabular}


Beban izin (allowable) yaitu:

$$
\mathrm{Q}_{\mathrm{all}}=\mathrm{Q}_{\mathrm{u}} / \mathrm{SF}
$$

dengan :

$\mathrm{Q}_{\text {all }} \quad=$ Beban ijin pondasi

$\mathrm{Q}_{\mathrm{u}} \quad=$ Beban ultimate pondasi

$\mathrm{SF} \quad=$ safety factor

\section{Daya Dukung Pondasi Metode Meyerhof}

Menurut Hakam (2008), banyak penelitipeneliti setelah Terzaghi yang mengusulkan teori tentang perhitungan daya dukung pondasi dangkal. Parameter tanah yang digunakan masih tetap, namun ada perbaikan untuk kasuskasus tertentu sehingga membuat rumusan menjadi umum.

Secara garis besar, teori-teori tersebut masih mengadopsi apa yang telah dituliskan oleh Terzaghi. Namun terdapat beberapa perubahan terutama mengenai faktor daya dukung. Meyerhof membentuk rumusan baru untuk ketiga faktor daya dukung.

Kapasitas daya dukung pondasi dangkal teori Meyerhof ditulis sebagai berikut:

$\mathrm{q}_{\mathrm{u}}=\mathrm{c} \cdot \mathrm{Nc}\left(\mathrm{s}_{\mathrm{c}} \cdot \mathrm{d}_{\mathrm{c}} \mathrm{i}_{\mathrm{c}}\right)+\mathrm{q}^{\prime} \cdot \mathrm{Nq} \cdot\left(\mathrm{s}_{\mathrm{q}} \cdot \mathrm{d}_{\mathrm{q}} \cdot \mathrm{i}_{\mathrm{q}}\right)+$

$$
1 / 2 \gamma \cdot \mathrm{B} . \mathrm{N} \gamma \cdot\left(\mathrm{s}_{\gamma} \cdot \mathrm{d}_{\gamma} \cdot \mathrm{i}_{\gamma}\right)
$$

dengan $\mathrm{Nc}, \mathrm{Nq}, \mathrm{N} \gamma$ adalah faktor kapasitas daya dukung Meyerhof tanpa satuan (nondimensional) yang didapatkan hanya dari nilai sudut geser dalam tanah (Ф). $\mathrm{s}_{\mathrm{c}}, \mathrm{d}_{\mathrm{c}}, \mathrm{i}_{\mathrm{c}}, \mathrm{d}_{\mathrm{q}}, \mathrm{i}_{\mathrm{q}}, \mathrm{s}_{\gamma}$, $\mathrm{d}_{\gamma}, \mathrm{i}_{\gamma}$ adalah faktor-faktor bentuk, kedalaman dan kemiringan beban seperti pada Tabel 3 .

Tabel 3. Faktor bentuh ( $\mathrm{s}=$ shape), kedalaman $(\mathrm{d}=$ depth) dan sudut beban (i=inclination) untuk rumus daya dukung Meyerhof

\begin{tabular}{lll}
\hline Faktor & Nilai $\varphi$ & Rumus \\
\hline Sc & Semua nilai & $\mathrm{Sc}=1+0,2 . \mathrm{Kp} .\left(\mathrm{B}^{\prime} / \mathrm{L}^{\prime}\right)$ \\
\hline \multirow{2}{*}{$\mathbf{S q}=\mathbf{S}_{\gamma}$} & $\varphi>10$ & $\mathrm{Sq}=\mathrm{S}_{\gamma}=1+0,1 . \mathrm{Kp} .\left(\mathrm{B}^{\prime} / \mathrm{L}^{\prime}\right)$ \\
\cline { 2 - 3 } & $\varphi=0$ & $\mathrm{Sq}=\mathrm{S}_{\gamma}=1$ \\
\hline $\mathbf{d c}$ & Semua nilai & $\mathrm{dc}=1+0,2(\mathrm{Kp})^{0,5}(\mathrm{D} / \mathrm{B})$ \\
\hline \multirow{2}{*}{$\mathbf{d q}=\mathbf{d}_{\gamma}$} & $\varphi>10$ & $\mathrm{dq}=\mathrm{d}_{\gamma}=1+0,1(\mathrm{Kp})^{0,5}(\mathrm{D} / \mathrm{B})$ \\
\cline { 2 - 3 } & $\varphi=0$ & $\mathrm{dq}=\mathrm{d}_{\gamma}=1$ \\
\hline \multirow{2}{*}{ ic $=$ iq } & Semua nilai & ic $=\mathrm{iq}=\left(1-\frac{\theta}{90}\right)^{2}$ \\
\hline $\mathrm{i}_{\gamma}$ & $\phi>0$ & $\mathrm{i}_{\gamma}=\left(1-\frac{\theta}{\phi}\right)^{2}$ \\
\cline { 2 - 3 } & $\phi=0$ & $\mathrm{i}_{\gamma}=0$ \\
\hline
\end{tabular}

Sumber : Hakam, (2008)
Nilai Kp yang digunakan Meyerhof adalah nilai dari Rankine,

$$
\mathrm{Kp}=\tan \frac{2 \pi}{4}+\frac{\varphi}{2}
$$

Sudut beban (inclinasi) adalah sudur yang dibuat oleh beban terpusat terhadap sumbu vertikal seperti pada Gambar 1.

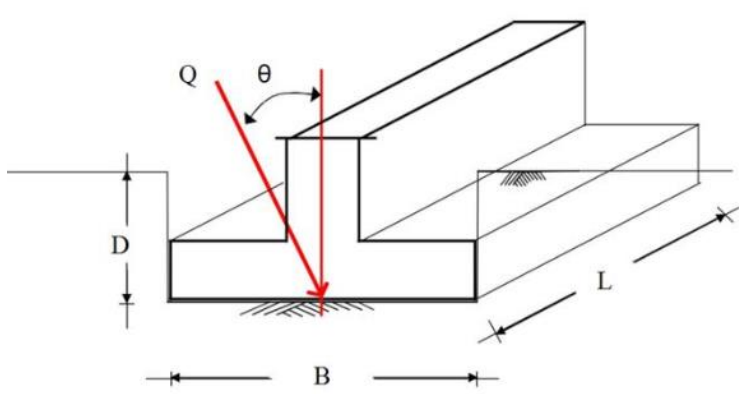

Gambar 1. Variabel pondasi telapak untuk rumus Meyerhof (Hakam, 2008)

Nilai faktor kapasitas daya dukung $\mathrm{Nc}, \mathrm{Nq}, \mathrm{N}_{\gamma}$ dari Meyerhof selanjutnya dapat dihitung dengan menggunakan persamaan-persamaan berikut:

$$
\begin{aligned}
& \mathrm{Nc}=(\mathrm{Nq}-1) \cot \varphi \\
& \mathrm{Nq}=\mathrm{e}^{\pi \tan \varphi} \mathrm{Kp} \\
& \mathrm{N} \gamma=(\mathrm{Nq}-1) \tan (1,4 \varphi)
\end{aligned}
$$

Tabel 4. Nilai Faktor Daya Dukung Meyerhof

\begin{tabular}{cccc}
\hline$\Phi$ & $\mathrm{Nc}$ & $\mathrm{Nq}$ & $\mathrm{N}_{\gamma \text {-Meyerhof }}$ \\
\hline 0 & 5,14 & 1,0 & 0,0 \\
\hline 5 & 6.59 & 1.57 & 0,1 \\
\hline 10 & 8.34 & 2.47 & 0.4 \\
\hline 15 & 10.98 & 3.94 & 1.1 \\
\hline 20 & 14.83 & 6.40 & 2.9 \\
\hline 21 & 15.81 & 7.07 & 3.4 \\
\hline 22 & 16.88 & 7.82 & 4.1 \\
\hline 23 & 18.05 & 8.66 & 4.8 \\
\hline 24 & 19.36 & 9.60 & 5.7 \\
\hline 25 & 20.72 & 10.66 & 6.8 \\
\hline 30 & 30.14 & 18.40 & 15.7 \\
\hline 35 & 46.12 & 33.30 & 37.2 \\
\hline 40 & 75.31 & 64.20 & 93.7 \\
\hline 45 & 133.87 & 134.87 & 262.6 \\
\hline 50 & 266.88 & 319.06 & 873.9 \\
\hline
\end{tabular}

Sumber : Hakam, (2008). 


\section{HASIL DAN PEMBAHASAN}

\subsection{Metode Terzaghi}

Dimensi pondasi :

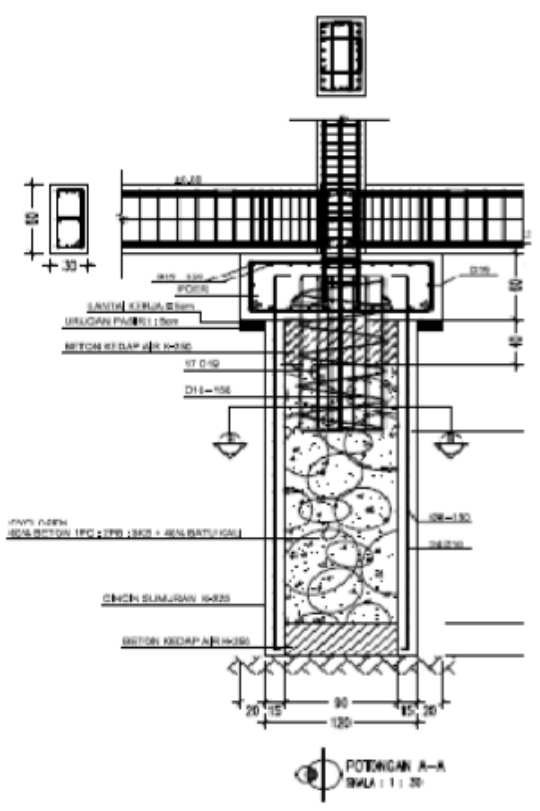

Gambar 3. Pondasi Sumuran 1 (PS1)

$$
\begin{array}{ll}
\mathrm{B} & =1,2 \mathrm{~m} \\
\mathrm{Df} & =3 \mathrm{~m} \\
\phi & =21 \\
\mathrm{Nc} & =19,18 \\
\mathrm{Nq} & =8,46 \\
\mathrm{~N}_{\gamma} & =5.94 \\
\gamma & =1,7 \mathrm{kN} / \mathrm{m}^{2} \\
\mathrm{c} & =266,66 \mathrm{kN} / \mathrm{m}^{2}
\end{array}
$$

daya dukung ultimate pondasi adalah:

$$
\begin{aligned}
\text { qult } & =1,3 \cdot c \cdot N c+\text { Df. } \gamma \cdot \mathrm{Nq}+0,6 \cdot B \cdot \gamma \cdot \mathrm{N}_{\gamma} \\
& =6699,32 \mathrm{kN} / \mathrm{m}^{2}
\end{aligned}
$$

Beban ultimate yang ditahan oleh pondasi :

$$
\begin{aligned}
\mathrm{Qu} & =\pi \cdot \mathrm{r}^{2} \cdot \mathrm{q}_{\mathrm{ult}} \\
& =7572,90 \mathrm{kN}
\end{aligned}
$$

Beban izin (allowable) untuk pondasi adalah :

$$
\begin{aligned}
\mathrm{Q}_{\text {all }} & =\mathrm{Qu} / \mathrm{SF} \\
& =7572,90 / 3=2524,30 \mathrm{kN} .
\end{aligned}
$$

\section{Metode Meyerhof}

Rangkuman data perhitungan:

$$
\begin{array}{ll}
\mathrm{B} & =1,2 \mathrm{~m} \\
\mathrm{Df} & =3 \mathrm{~m} \\
\phi \quad & =21 \\
\mathrm{Nc} & =15,81 \\
\mathrm{Nq} & =7,07 \\
\mathrm{~N}_{\gamma} & =3,4 \\
\gamma & =1,7 \mathrm{kN} / \mathrm{m}^{2} \\
\mathrm{c} & =266,66 \mathrm{kN} / \mathrm{m}^{2} \\
\mathrm{Kp} & =0,036 \\
\mathrm{dc} & =1,0948 \\
\mathrm{sc} & =1,0028 \\
\mathrm{dq}=\mathrm{d}_{\gamma} & =1,0474 \\
\mathrm{sq}=\mathrm{s}_{\gamma} & =1,0014 \\
\mathrm{i}_{\mathrm{c}}=\mathrm{i}_{\mathrm{q}} & =1 \\
\mathrm{i}_{\gamma} & =0
\end{array}
$$

kapasitas daya dukung ultimate adalah

$$
\begin{aligned}
& \mathrm{q}_{\mathrm{u}}=\mathrm{c} \cdot \mathrm{Nc}\left(\mathrm{s}_{\mathrm{c}} \cdot \mathrm{d}_{\mathrm{c}} \mathrm{i}_{\mathrm{c}}\right)+\mathrm{q}^{\prime} \cdot \mathrm{Nq} \cdot\left(\mathrm{s}_{\mathrm{q}} \cdot \mathrm{d}_{\mathrm{q}} \mathrm{i}_{\mathrm{q}}\right)+1 / 2 \\
& \gamma \cdot \mathrm{B} . \mathrm{N} \gamma \cdot\left(\mathrm{s}_{\gamma} \cdot \mathrm{d}_{\gamma} \cdot \mathrm{i}_{\gamma}\right) \\
& =4669,77 \mathrm{kN}
\end{aligned}
$$

Beban ultimate yang ditahan oleh pondasi :

$$
\begin{aligned}
\mathrm{Qu} & =\pi \cdot \mathrm{r}^{2} \cdot \mathrm{q}_{\mathrm{ult}} \\
& =5278,71 \mathrm{kN}
\end{aligned}
$$

Beban izin (allowable) untuk pondasi adalah :

$$
\begin{aligned}
\text { Qall } & =\mathrm{Qu} / \mathrm{SF} \\
& =5278,71 / 3 \\
& =1759,57 \mathrm{kN} .
\end{aligned}
$$

Rekap dari hasil perhitungan beban izin pondasi dengan metode Terzaghi dan metode Meyerhof dapat dilihat dari Tabel 5 sebagai berikut :

Tabel 5. Beban izin (Qall) terhadap kedalaman pondasi

\begin{tabular}{ccc}
\hline \multirow{2}{*}{$\begin{array}{c}\text { Kedalaman } \\
(\mathbf{m})\end{array}$} & \multicolumn{2}{c}{ Beban Izin (Qall) $(\mathbf{k N})$} \\
\cline { 2 - 3 } & Terzaghi & Meyerhof \\
\hline $\mathbf{3 , 0}$ & 2524,30 & 1759,57 \\
\hline
\end{tabular}




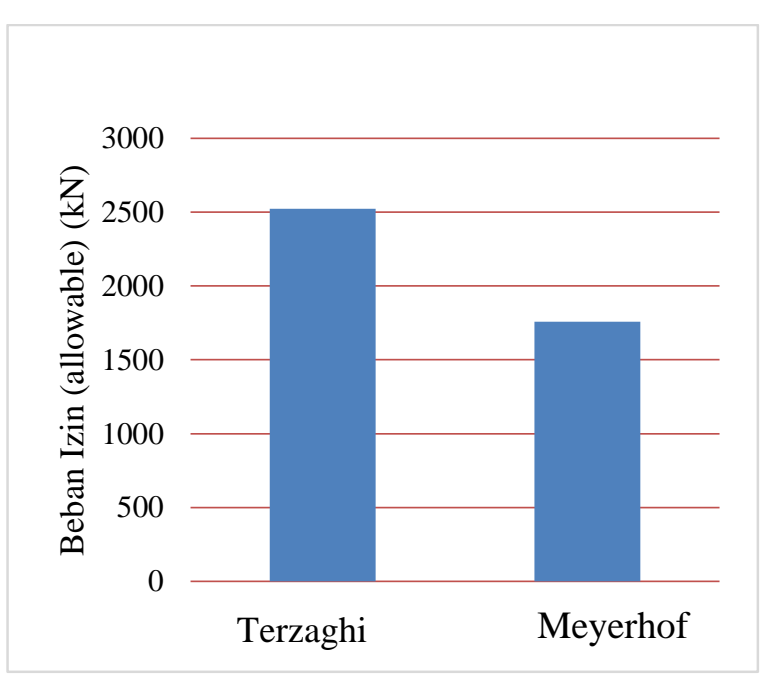

Gambar 4. Diagram Beban Izin (Qall)

Berdasarkan dari Tabel 5 dan Gambar 4. dapat dilihat hasil perhitungan daya dukung izin pondasi dengan metode Terzaghi dan metode Meyerhof pada kedalaman pondasi 3,0 m dengan pondasi sumuran, diameter 1,2 $\mathrm{m}$. Dari kedua metode tersebut, terdapat perbedaan hasil nilai daya dukung izin (Qall) pada pondasi tersebut. Hal ini disebabkan perbedaan koefisien-koefisien yang digunakan untuk masing-masing metode. Metode Terzaghi menghitung daya dukung pondasi dengan mempertimbangkan faktor bentuk dari bentuk pondasi ( $\mathrm{s}_{\mathrm{c}}$ dan $\left.\mathrm{s}_{\gamma}\right)$. Sedangkan metode Meyerhof, koefisien yang digunakan dalam mendapatkan daya dukung pondasi dipengaruhi oleh faktor bentuk pondasi $\left(\mathrm{s}_{\mathrm{c}}, \mathrm{s}_{\mathrm{q}}\right.$, $\mathrm{s}_{\gamma}$ ), faktor bentuk pondasi $\left(\mathrm{d}_{\mathrm{c}}, \mathrm{d}_{\mathrm{q}}, \mathrm{d}_{\gamma}\right)$, dan faktor kemiringan beban $\left(i_{c}, i_{q}, i_{\gamma}\right)$.

\section{KESIMPULAN}

Berdasarkan hasil penelitian, maka dapat disimpulkan sebagai berikut :

1. Jenis pondasi yang ditinjau dari penelitian ini adalah pondasi sumuran dengan diameter 1,2 $\mathrm{m}$ dan kedalaman $3 \mathrm{~m}$.

2. Daya dukung izin (Qall) dengan metode Terzaghi diperoleh sebesar 2524,30 kN, dan metode Meyerhof sebesar 1759,57 $\mathrm{kN}$.

3. Perbedaan hasil daya dukung yang diperoleh disebabkan nilai koefisienkoefisien yang digunakan berbeda.

4. Metode Terzaghi memperhitung faktor bentuk pondasi $\left(s_{c}\right.$ dan $s_{\gamma}$ ). Sedangkan metode Meyerhof, koefisien yang digunakan dalam mendapatkan daya dukung pondasi dipengaruhi oleh faktor bentuk pondasi $\left(\mathrm{s}_{\mathrm{c}}, \mathrm{s}_{\mathrm{q}}, \mathrm{s}_{\gamma}\right)$, faktor bentuk pondasi $\left(\mathrm{d}_{\mathrm{c}}, \mathrm{d}_{\mathrm{q}}, \mathrm{d}_{\gamma}\right)$, dan faktor kemiringan beban $\left(\mathrm{i}_{\mathrm{c}}, \mathrm{i}_{\mathrm{q}}, \mathrm{i}_{\gamma}\right)$.

\section{UCAPAN TERIMA KASIH}

Ucapan terima kasih kepada pihak-pihak yang membantu dalam penelitian ini sehingga penulis dapat melakukan penelitian dengan baik dan lancar.

\section{DAFTAR PUSTAKA}

Asroni, A. (2010). Kolom Fondasi \& Balok T Beton Bertulang. Penerbit Graha Ilmu. Yogyakarta: Cetakan Pertama.

Bahtiar, M. A., Surjandari, N. S., \& Setiono, S. (2016). Korelasi Nilai Kohesi dan Sudut Geser dalam dengan Nilai Tahanan Konus Sondir Menggunakan Metode Statistika. E- Jurnal Matriks Teknik Sipil, 4(3), pp. 690-698. https://jurnal.uns.ac.id/matriks/ article/view/37073

Roschedy, G., Manoppo, F. J., \& Mandagi, A. T. (2019). Analisis Daya Dukung Pondasi Jembatan Gorr I. Jurnal Sipil Statik Jurusan Sipil Fakultas Teknik Universitas Sam Ratulangi Manado, 7(4), pp. 397408. https://ejournal.unsrat.ac.id/index. $\mathrm{php} / \mathrm{jss} / \mathrm{article} / \mathrm{view} / 23390$

Hakam, A. (2008). Rekayasa Pondasi. CV. Bintang Grafika. Padang.

Martini, M. (2009). Analisis Daya Dukung Tanah Pondasi Dangkal dengan Beberapa Metode. Majalah Ilmiah Mektek Universitas Tadulako Manado, 11(2), pp. 75-87. http://jurnal.untad.ac.id/jurnal/ index.php/Mektek/article/view/512

Alwalan, M. F. (2018). Interaction of Closely Spaced Foundations on Sands and Clasys: A review. International Journal of Advanced Engineering Research and Science (IJAERS), 5(9), pp. 101-110. DOI:10.22161/ijaers.5.9.11 
Muda, A. (2016). Analisis Daya Dukung Tanah Fondasi Dangkal Berdasarkan Data Laboratorium. Jurnal INTEKNA: Informasi Teknik dan Niaga Politeknik Negeri Banjarmasin, 16(1), pp. 1-16. https://ejurnal.poliban.ac.id/index.php/ intekna/article/view/321

Nurdian, S., Setyanto, S., \& Afriani, L. (2015). Korelasi Parameter Kekuatan Geser Tanah dengan Menggunakan Uji Triaksial dan Uji Geser Lempung Substitusi Pasir. Journal Rekayasa Sipil Dan Desain (JRSDD), 3(1), pp. 13-26. https://journal.eng.unila.ac.id/index.php/ jrsdd/article/view/353
Padmini, P. (2018). Review of Methode to Predict the Bearing of Shallow Foundation. International Research Journal of Engineering and Technology (IRJET), 5(11), pp. 217-226.

Ridar, M., \& Khatib, A. (2015). Tinjauan Daya Dukung dan Penurunan Pondasi Sumuran di Pemuda City Walk di Jl. Pemuda Pekanbaru Provinsi Riau. Jurnal Saintis Program Studi Teknik Sipil Universitas Islam Riau, 15(1), pp. 81-92. https://journal.uir.ac.id/index.php/saintis/ article/view/3173

Surendro, B. (2015). Rekayasa Fondasi. Graha Ilmu. Yogyakarta : Cetakan Pertama. 